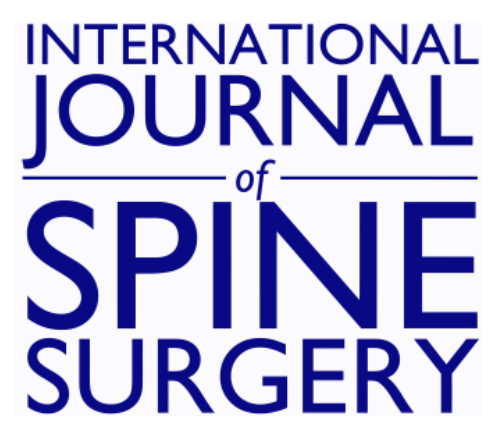

\title{
Trending Literature in Spinal Tuberculosis: Bibliographic Analysis of Top 250 Cited Articles
}

MUTHU SATHISH and RAMAKRISHNAN ESWAR

Int J Spine Surg 2020, 14 (5) 838-846

doi: https://doi.org/10.14444/7119

http://ijssurgery.com/content/14/5/838

This information is current as of April 25, 2023.

Email Alerts Receive free email-alerts when new articles cite this article. Sign up at:

http://ijssurgery.com/alerts

The International Journal of Spine Surgery

2397 Waterbury Circle, Suite 1,

Aurora, IL 60504, Phone: +1-630-375-1432 


\title{
Trending Literature in Spinal Tuberculosis: Bibliographic Analysis of Top 250 Cited Articles
}

\author{
MUTHU SATHISH, MS ORTHO, ${ }^{1}$ RAMAKRISHNAN ESWAR, MBBS ${ }^{2}$ \\ ${ }^{I}$ Government Hospital, Velayuthampalayam, Karur, Tamil Nadu, India, ${ }^{2}$ Institute of Orthopaedics and Traumatology, Madras Medical College \& Rajiv Gandhi \\ Government General Hospital, Chennai, India
}

\begin{abstract}
Background: This bibliographic analysis aims to identify the top 250 cited articles on spinal tuberculosis (TB) and report on their impact on the spinal field.

Methods: All databases included in the Thomson Reuters Web of Science were searched for publications on spinal TB. The most cited articles published between 1950 and 2019, with the main focus on orthopaedic surgery, were identified using a multistep approach, and a total of 250 articles were included and analyzed for title, year of publication, total citations, citations in 2019, citation density, article age, journal, first author, senior author, geographic origin, and level of evidence.

Results: The number of citations ranged from 31 to 257 , with an average of 65.38 . Studies were published from 31 different countries and published in 83 different journals. The top 3 countries, India, United States, and China published a total of $57.8 \%(n=145)$ of all articles. Indian and Chinese researchers seem to be the most resourceful, as 17 of the 31 $(54.8 \%)$ prospective studies were conducted by them. African centers produced only $3.2 \%(\mathrm{n}=8)$ of all included articles. Only $3.2 \%(n=8)$ were of Level 1 evidence on the subject. A total of $37.8 \%(n=95)$ were on diagnosis, while $46.6 \%(n=$ 117) dealt with surgery, and only $15.1 \%(n=38)$ were about conservative management. Anil K Jain followed by $\mathrm{S}$ Rajasekaran were the most published authors on the subject.

Conclusions: Indian and Chinese researchers dominate evidence in spinal TB. Regions with high disease burden, such as Africa, do not contribute their data to the literature. Though these are the top cited articles in the subject, their level of evidence needs improvement for better impact of their results.
\end{abstract}

Other \& Special Categories

Keywords: citation analysis, TB

\section{INTRODUCTION}

A global increase in the incidence of tuberculosis (TB) has been reported, ${ }^{1,2}$ despite the disease being more common in the low- to middle-income countries, as shown in Figure $1 .^{3}$ Due to increase in mobility of travelers day by day, TB remains a global challenge and is the top infectious killer disease worldwide. ${ }^{3,4}$ Spinal TB is the most common form of skeletal $\mathrm{TB}^{5,6}$ and is the common cause of ailments in the spine in developing countries. Countries like India and China, with their developing economies, have put more effort on medical research, which is not the case with most low-income countries, although they get the brunt of the disease. ${ }^{7}$ However, it is challenging for them to address the clinical burden of endemic diseases without having their own evidence and solutions, which has been highlighted by Wang et $\mathrm{al}^{5}$ in their analysis of the research trend in spinal TB between 1994-2015.
Bibliometrics uses the literature system and metrology characteristics as research objects and analyzes the literature both quantitatively and qualitatively $^{8}$ and has played a fundamental role in the past to govern policymaking, clinical guidelines, and research trends. Hence, it can be used as a tool to analyze the influence of research articles by quantitative appraisal of their impact $^{8}$ on TB research $^{9}$ as well as on spinal surgery. ${ }^{10}$ The objective of this study is to identify the 250 most cited research articles in spinal TB and analyze their characteristics.

\section{METHODOLOGY}

From all available databases of the Thomson Reuters Web of Science, we selected the 250 most cited articles on spinal TB between 1950 and 2019 with a multistep selection process. Ethical approval was not necessary since the data were downloaded 


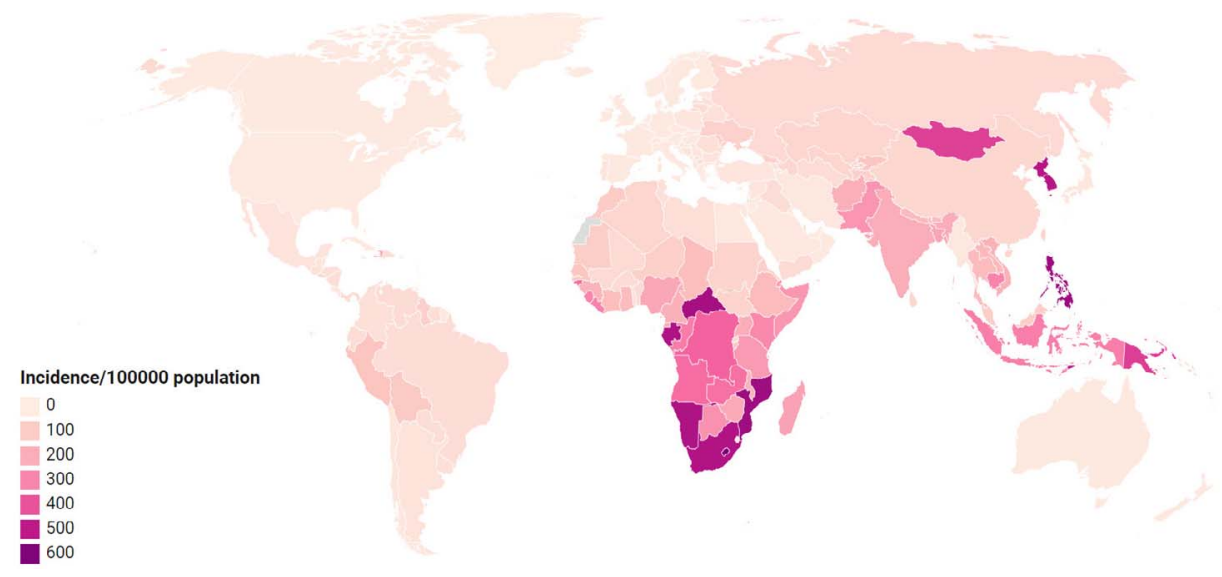

Figure 1. The global burden of tuberculosis in terms of incidence of tuberculosis per country. Data source: World Health Organization—Global Tuberculosis Report $2019 .^{5}$

from public databases. Preferred Reporting Items for Systematic Reviews and Meta-Analyses (PRISMA) and Meta-Analysis of Observational Studies in Epidemiology guidelines were followed in the conduct and reporting of the study.

\section{Selection Process}

The selection process was done by 2 reviewers using a topic and title search in the "all database" of the Thomson Reuters Web of Science. Terms used during the search were: Theme $=\left(\left(\right.\right.$ Spin* $^{*}$ AND Tuberculosis) OR (Pott* AND Disease) OR (Pott's Paraplegia)) AND publishing year $=(1950-2019)$. We used theme search to include articles on spinal TB without the specific word in their titles. An asterisk was used to include all relevant extensions of the word. For example, vertebr* will search for vertebral and vertebrae. The 250 most cited articles were then shortlisted for further analysis from the list of 14376 articles based on the consecutive ranking of their citation rate following the multistep selection process, as shown in the PRISMA flow Figure 2.

All articles with focus on the clinical course or treatment of spinal TB were included. Articles on all age groups were included. All articles not predominantly focusing on spinal TB were excluded. This was the case with articles on spinal infections caused by various pathogens with only a minority of $\mathrm{TB}$ infections.

\section{Analysis}

For each study included, both authors extracted in duplicate and systematically analyzed the follow- ing parameters: title, year of publication, total citations, citations in 2019, citation density (citation number divided by the article age), article age, journal, first author, senior author, geographic origin, and level of evidence. In the case of only a single author, the author was considered both the first and senior author.

The level of evidence was established using the Journal of Bone and Joint Surgery. American Volume $^{11}$ ranking, with Level 1 being the strongest and Level 5 being the weakest level of evidence.

Articles were first divided into 3 categories based on those dealing with: diagnosis, medical, or surgical management. We also categorized the nature of the article into 3 categories: prospective, retrospective, and descriptive. We ranked all articles according to their total citation number, number 1 having the highest number of citations and number 250 having the lowest. In case of an equal number, the articles were ranked according to citations in 2019 and citation density.

\section{RESULTS}

The number of citations ranged from 31 to 257 , with an average of 65.38 . The articles were published in 83 different journals, as shown in Table 1, and the studies were conducted in 31 different countries, as shown in Table 2. All articles were published in the English language.

\section{Top 100}

Citation of the top 100 articles ranged from 60 to 257. The articles were published between 1960 and 


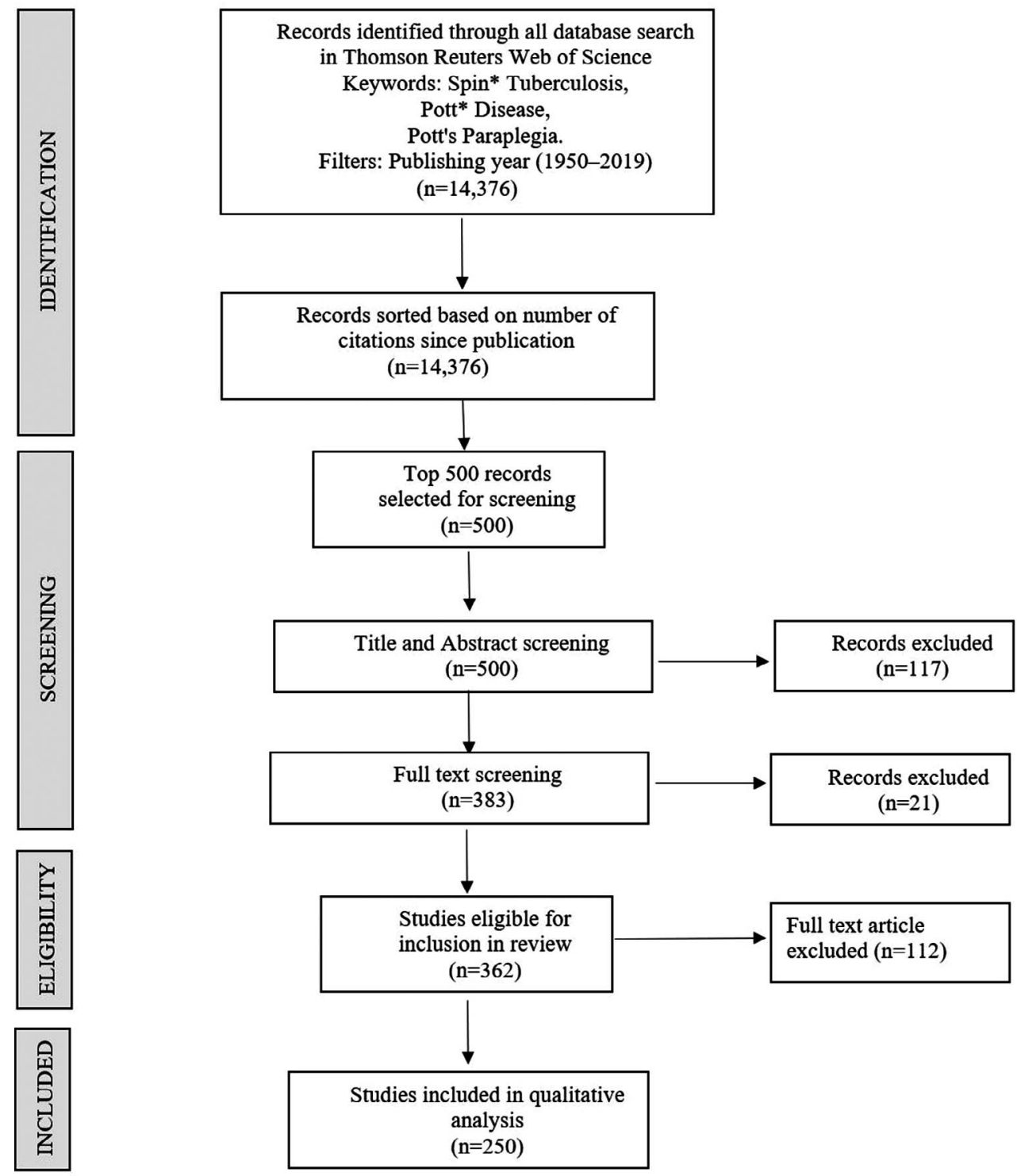

Figure 2. The Preferred Reporting Items for Systematic Reviews and Meta-Analyses flow diagram for selection of studies included in the review.

2012 and had an average age of 22.84 years. The major contributing journals to the top 100 were the Journal of Bone and Joint Surgery. British Volume (n =14), Spine Journal $(\mathrm{n}=12)$, Clinical Orthopaedics and Related Research $(\mathrm{n}=6)$, and the Journal of Bone and Joint Surgery. American Volume $(\mathrm{n}=6)$. Among the top 100 articles, the top 3 contributions were from India $(25 \%)$, United States $(18 \%)$, and China (16\%), as shown in Table 3.

The top 10 articles $^{12-21}$ from 250 selected articles were listed in Table 4. The most cited article was written by Hodgson et $\mathrm{al}^{12}$ in 1960 , in the British Journal of Surgery with 257 citations. It explains the pathological findings of spinal TB in 412 patients and the operative approach for anterior spinal fusion.

\section{Article Age}

The mean age of the articles included in the selection was 20.81 years ( $\mathrm{SD}=12.3$ years) with the age range between 4 and 69 years. The oldest article included in our list was published in 1950 and written by Burke. ${ }^{22}$ It was cited 36 times and has a citation density of 0.51 , with 0 citations in 2019 . The most recent article included, published in 2015 , is by Papadopoulos et $\mathrm{al}^{23}$, with a citation number of 35 and a citation density of 7 . Most articles were published between 2001 and $2010(\mathrm{n}=111,44.4 \%)$, and a total of 112 articles $(44.8 \%)$ were published before 2001. The publication trend of the selected articles is shown in Figure 3. 
Table 1. The journal contribution to the top 250 articles on spinal tuberculosis.

\begin{tabular}{lcc}
\hline & $\begin{array}{c}\text { No. } \\
\text { Articles }\end{array}$ & $\begin{array}{c}\text { \% of } \\
\text { Top 250 }\end{array}$ \\
Journal Name & 35 & 14.0 \\
\hline Spine & 27 & 10.8 \\
Journal of Bone and Joint Surgery. British Volume & 16 & 6.4 \\
Clinical Orthopaedics and Related Research & 14 & 5.6 \\
International Orthopaedics & 13 & 5.2 \\
European Spine Journal & 12 & 4.8 \\
Journal of Bone and Joint Surgery. American Volume & 7 & 2.8 \\
Journal of Spinal Disorders \& Techniques & 7 & 2.8 \\
Radiologic Clinics of North America & 6 & 2.4 \\
Neurosurgery & 6 & 2.4 \\
Radiology & 5 & 2.0 \\
Journal of Neurosurgery & 4 & 1.6 \\
American Journal of Roentgenology & 4 & 1.6 \\
Journal of Neurosurgery-Spine & 4 & 1.6 \\
Spinal Cord & 3 & 1.2 \\
Acta Orthopaedica Scandinavica & 3 & 1.2 \\
Archives of Orthopaedic and Trauma Surgery & 3 & 1.2 \\
European Radiology & 3 & 1.2 \\
Indian Journal of Orthopaedics & 3 & 1.2 \\
Orthopedic Clinics of North America & 2 & 0.8 \\
Acta Radiologica & 2 & 0.8 \\
American Journal of Neuroradiology & 2 & 0.8 \\
American Journal of Physical Anthropology & 2 & 0.8 \\
Childs Nervous System & 2 & 0.8 \\
Clinical Infectious Diseases & 2 & 0.8 \\
Clinical Neurology and Neurosurgery & 2 & 0.8 \\
Clinical Radiology & 2 & 0.8 \\
European Journal of Radiology & 2 & 0.8 \\
Journal of Computer Assisted Tomography & 2 & 0.8 \\
Journal of Infection & 0.8 \\
Skeletal Radiology & 21.2 \\
Others & & \\
Total & \\
\hline & \\
& & \\
& &
\end{tabular}

Table 2. The country-wise contribution to the top 250 articles on spinal tuberculosis.

\begin{tabular}{lcc}
\hline Country & No. Articles & \% of Top 250 \\
\hline India & 56 & 22.3 \\
United States & 55 & 21.9 \\
China & 34 & 13.6 \\
Korea & 15 & 6 \\
Germany & 11 & 4.4 \\
Saudi & 10 & 4 \\
Turkey & 10 & 4 \\
United Kingdom & 9 & 3.6 \\
South Africa & 8 & 3.2 \\
Spain & 6 & 2.4 \\
Canada & 4 & 1.6 \\
Italy & 4 & 1.6 \\
Belgium & 3 & 1.2 \\
France & 3 & 1.2 \\
Greece & 3 & 1.2 \\
Japan & 3 & 1.2 \\
Argentina & 2 & 0.8 \\
England & 2 & 0.8 \\
Netherlands & 2 & 0.8 \\
Australia & 1 & 0.4 \\
Denmark & 1 & 0.4 \\
Kuwait & 1 & 0.4 \\
Nepal & 1 & 0.4 \\
Norway & 1 & 0.4 \\
Pakistan & 1 & 0.4 \\
Portugal & 1 & 0.4 \\
Sweden & 1 & 0.4 \\
Switzerland & 1 & 0.4 \\
Thailand & 1 & 0.4 \\
Total & 250 & 100 \\
\hline
\end{tabular}

Table 3. Top 100 publications in spinal tuberculosis .

\begin{tabular}{llc}
\hline Category & \multicolumn{1}{c}{ Top 100 Publications } & $\begin{array}{c}\text { \% of } \\
\text { Top 100 }\end{array}$ \\
\hline Top country & India & 25 \\
& United States & 18 \\
& China & 16 \\
Korea & 8 \\
Top journal & Journal of Bone and Joint & 14 \\
& $\quad$ Surgery. British Volume & \\
Top publication year & Spine & 12 \\
& 1995 & 7 \\
Top author & Jain AK & 7 \\
& Rajasekaran S & 6 \\
Top level of evidence & Leong CY & 6 \\
Top study type & Level 4 & 4 \\
Top study category & Retrospective & 39 \\
\hline
\end{tabular}

\section{Geographic Origin}

A total of 29 different countries were identified from the top 250 articles. The geographic origin responsible for most publications was India $(\mathrm{n}=$ $56 ; 22.3 \%$ ), followed by the United States $(\mathrm{n}=55$; $21.9 \%)$ and China $(\mathrm{n}=34 ; 13.6 \%)$, as shown in Figure 4. Together, researchers from these countries published a total of 141 articles $(58 \%)$ of our selection. Of the 34 articles originating from China, 13 (5.2\%) were from Hong Kong. Authors from Asia published the most articles with 48.6\% $(\mathrm{n}=122)$, followed by North America 23.5\% $(\mathrm{n}=$ 59), Europe 23.1\% $(\mathrm{n}=58)$, and Africa 3.2\% $(\mathrm{n}=$ 8).

\section{Journals}

Most articles were published by Spine Journal with 27 publications $(\mathrm{n}=35,14 \%)$, followed by the Journal of Bone and Joint Surgery. British Volume (n $=27,10.8 \%)$, Clinical Orthopaedics and Related Research $(\mathrm{n}=16,6.4 \%)$, International Orthopaedics $(\mathrm{n}=14,5.6 \%)$ and European Spine Journal $(\mathrm{n}=13$, $5.2 \%)$. These 5 of the 83 journals in our selection produced $42 \%(\mathrm{n}=105)$ of the included articles.

\section{Authorship}

A total of 20 authors in our list published 2 or more articles, as shown in Table 5. Jain ${ }^{14}$, from India, is the most published author with a total of 10 publications (4\%), 6 as first author and 4 as first and senior author. Rajasekaran ${ }^{17}$ and $\mathrm{Tuli}^{24}$ have published 9 and 7 articles, respectively, and were listed as the second and third most published authors on the subject. 
Table 4. The top 10 articles on tuberculosis spine based on their citations.

\begin{tabular}{|c|c|c|c|c|}
\hline No. & Article & $\begin{array}{l}\text { Total } \\
\text { Citations }\end{array}$ & $\begin{array}{l}\text { Citations } \\
\text { in } 2019\end{array}$ & $\begin{array}{l}\text { Citation } \\
\text { Rate }\end{array}$ \\
\hline 1 & $\begin{array}{l}\text { The operative approach and pathological findings in } 412 \text { patients with Pott's disease of the spine by } \\
\text { Hodgson AR et al. published in Br J Surg. }{ }^{12}\end{array}$ & 257 & 8 & 4.28 \\
\hline 2 & $\begin{array}{l}\text { Anterior spine fusion for the treatment of tuberculosis of the spine- the operative findings and results of } \\
\text { treatment in the } 1 \text { st } 100 \text { cases by Hodgson AR et al. published in } J \text { Bone Joint Surg Am. }{ }^{13}\end{array}$ & 237 & 4 & 3.95 \\
\hline 3 & Tuberculosis of the spine: a fresh look at an old disease by Jain AK published in $J$ Bone Joint Surg $\mathrm{Br}^{14}$ & 229 & 23 & 22.9 \\
\hline 4 & $\begin{array}{l}\text { Moon MS. Tuberculosis of the spine. Controversies and a new challenge by Moon MS published in Spine } \\
\quad(\text { Phila } \mathrm{Pa} 1976)^{15}\end{array}$ & 225 & 8 & 9.78 \\
\hline 5 & $\begin{array}{l}\text { Posterior instrumentation and anterior interbody fusion for tuberculous kyphosis of dorsal and lumbar } \\
\text { spines by Moon MS et al. published in Spine (Phila Pa 1976) }\end{array}$ & 220 & 6 & 8.8 \\
\hline 6 & $\begin{array}{l}\text { Progression of kyphosis in tuberculosis of the spine treated by anterior arthrodesis by Rajasekaran S et al. } \\
\text { published in } J \text { Bone Joint Surg } \mathrm{Am}^{17}\end{array}$ & 181 & 4 & 5.84 \\
\hline 7 & $\begin{array}{l}\text { Anterior instrumentation for the treatment of spinal tuberculosis by Yilmaz } \mathrm{C} \text { et al. published in } J \text { Bone } \\
\text { Joint Surg } \mathrm{Am}^{18}\end{array}$ & 173 & 2 & 8.24 \\
\hline 8 & $\begin{array}{l}\text { Spinal tuberculosis (Pott's disease): its clinical presentation, surgical management, and outcome. A survey } \\
\text { study on } 694 \text { patients by Turgut M published in Neurosurg Rev }{ }^{19}\end{array}$ & 170 & 12 & 8.95 \\
\hline 9 & Infectious agents in spinal epidural abscesses by Kaufman DM et al. published in Neurology. ${ }^{20}$ & 161 & 1 & 4.03 \\
\hline 10 & Modern management of spinal tuberculosis by Rezai AR et al. published in Neurosurgery. ${ }^{21}$ & 154 & 4 & 6.16 \\
\hline
\end{tabular}

\section{Level of Evidence}

A total of $44 \%(n=110)$ of the top 250 articles were of Level 4 evidence; $85.6 \%$ of articles of articles were Level 3 evidence and below. Only 3.2\% $(n=8)$ of our list were of Level 1 evidence. Out of 8 Level 1 studies, 4 were from India. Their area of research varied from clinical course $(n=2)$, imaging $(\mathrm{n}=2)$, medical management $(\mathrm{n}=1)$, and surgical technique $(\mathrm{n}=3)$.

\section{Study Type}

Most studies were of retrospective nature $(\mathrm{n}=$ $185,73.3 \%)$, while $12.4 \%$ articles $(n=31)$ were prospective clinical studies, of which only $4.8 \%$ were randomized controlled trials $(\mathrm{n}=12)$. A total of $13.5 \%$ articles $(n=34)$ were descriptive studies. A total of $37.8 \%(n=95)$ were categorized as dealing with diagnosis of the disease, while $46.6 \%(n=117)$ dealt with surgical management, and only $15.1 \%$ (n $=38$ ) were on conservative management.

\section{DISCUSSION}

\section{Article Age}

The oldest article in our list was published 70 years ago, written by Burke ${ }^{22}$. It is ranked 195 in our list with 36 citations and might be outdated when compared to the mean age of all articles of 20.8 years. This is supported by the fact that it has not received citations in 2019, while the latest article in the list was published at 2015. Hence, a minimum of a 4-year interval is need for articles to gain adequate citation to get a place in the top 250 list. Citation analysis of the top 5 articles of our selection has been depicted in Figure 5.

\section{Geographic Origin}

Most publications $(\mathrm{n}=56 ; 22.3 \%)$ in our list are from India, a country listed by the World Health Organization (WHO) as a high-burden country in the incidence and prevalence of $\mathrm{TB}$ as well as multidrug resistance TB and TB-human immuno-

\section{Publication Trend Analysis}

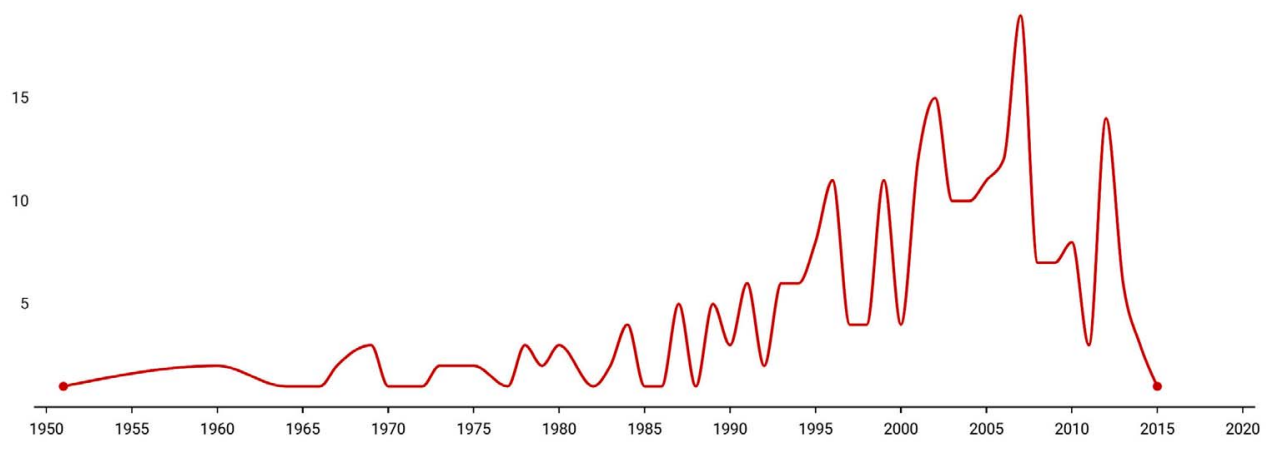

Figure 3. The publication trend analysis of the top 250 cited articles on spinal tuberculosis. 

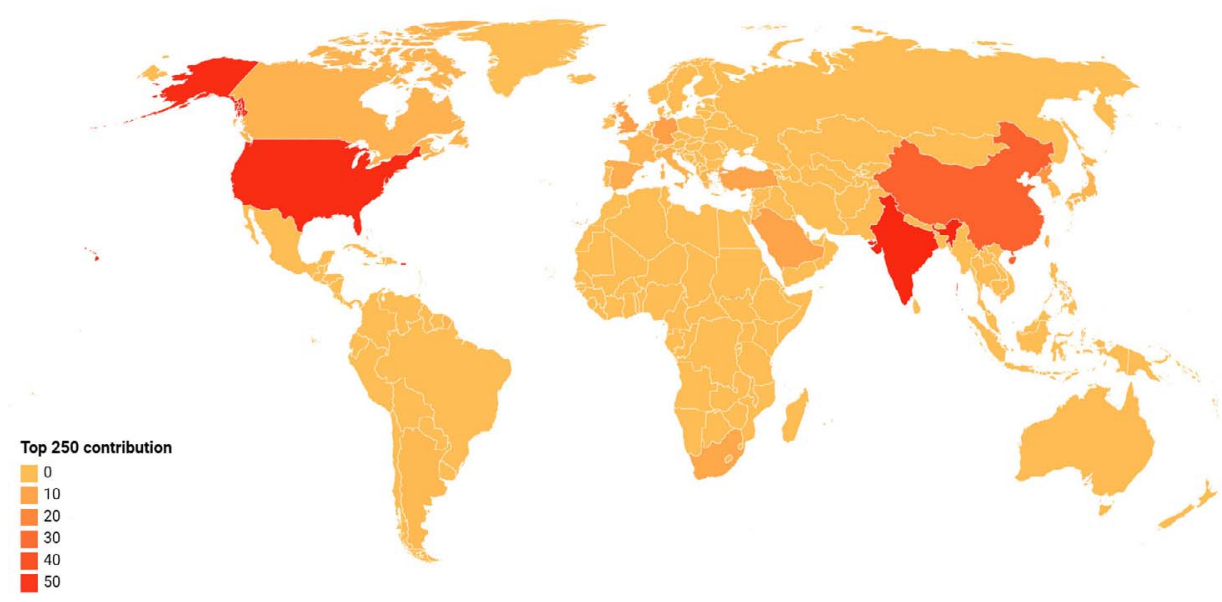

Figure 4. The global contribution of the top 250 cited articles on spinal tuberculosis.

deficiency virus (HIV) coinfection. ${ }^{3}$ India is followed by the United States, responsible for 55 articles $(21.9 \%)$. Although the United States faces severe TB outbreaks, ${ }^{25}$ it is not listed as a highburden country by the WHO. China is among the top 3 countries with 34 publications (13.6\%). Hong Kong published 13 of these 34 articles (38.2\%), which included the milestone work of Hodgson ${ }^{12}$, establishing early and radical anterior debridement as the gold standard for surgical management of spinal TB. China is listed both as a high-burden TB country with a high multidrug resistance $\mathrm{TB}$ and HIV-TB coinfection. ${ }^{3,5}$

On the other hand, only 8 publications $(3.2 \%)$ originate from the continent of Africa, all of them

Table 5. The author contribution in the top 250 articles on spinal tuberculosis.

\begin{tabular}{|c|c|c|c|}
\hline Author & $\begin{array}{c}\text { Total } \\
\text { Publications }\end{array}$ & First Author & Senior Author \\
\hline
\end{tabular}

Jain AK

Rajasekaran S

Tuli SM

Moon MS

Leong CY

Hsu LCS

Zhang HQ

Hodgson AR

Lifeso RM

Ha KY

Sun DH

Upadhyay SS

Sharif HS

Chen WJ

Nene A

Bhojraj S

Sundararaj GD

Benli IT

Jutte PC

Griffith DL being conducted in South Africa. Africa has one of the highest TB burdens and highest TB-HIV coinfection rates worldwide, yet there is a discrepancy between clinical experience and published research. This might point toward insufficient resources available to African institutions to conduct research or publish their experience, which is supported by WHO data on the funding gap in research in Africa. ${ }^{3}$

\section{Gap in Literature}

Our analysis shows that retrospective research remains important evidence in literature on spinal $\mathrm{TB}$ and is of high value to conduct them. We also found prospective clinical research studies and randomized controlled trials were very scarce, and research in the future should fill this gap. The latest data published by Treatment Action Group showed a funding gap for TB research and development of $\$ 1.2$ billion in the year 2017 , despite fixing the target of at least $\$ 2$ billion per year by the United Nations' high-level meeting on TB. ${ }^{3}$ Held et $a 1,{ }^{26}$ in their analysis of the most influential literature on spinal $\mathrm{TB}$, found that most centers in high-burden areas had no access to funding and extensive laboratory support to conduct basic science research or large randomized controlled trials and advocated for its improvement in the future, which was further emphasized by the results of our study.

The most popular area of research was on the surgical management of spinal TB $(n=117,46.6 \%)$, focusing on the operative management of the disease and its complications. The second most 


\section{Citation Trend Analysis}

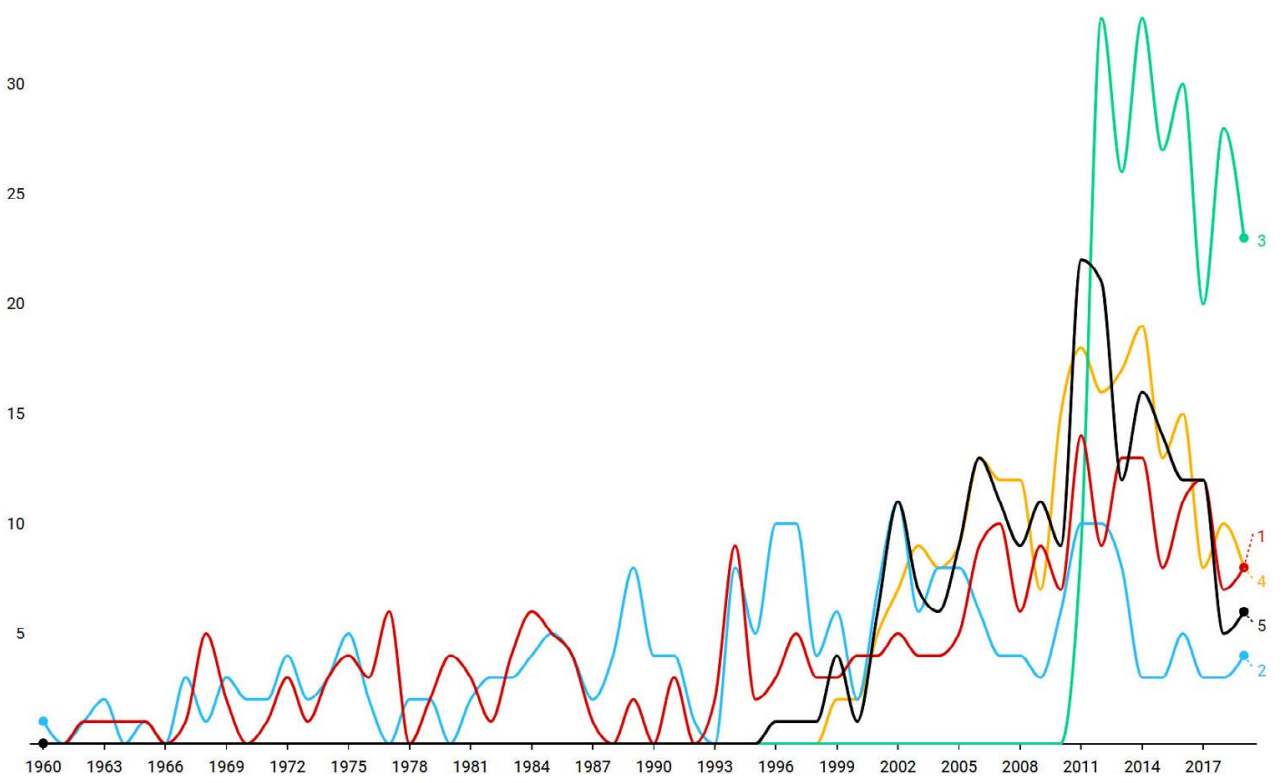

Figure 5. The citation trend analysis of the top 5 articles cited on spinal tuberculosis.

popular area was on clinical course and diagnostic imaging $(\mathrm{n}=95,37.8 \%)$, while only 38 articles dealt with conservative management of spinal TB $(15.1 \%)$. This shows that there is a lack of literature and research on the medical management of this medical disease, despite the alarming rise in multidrug-resistant TB globally. ${ }^{5}$

\section{Directions for Future Research}

Most studies were of retrospective nature, which would have been conducted in resource-restrained areas, where little funding and equipment were available, and randomized controlled trials are hard to set up. Indian and Chinese researchers seem to be the most resourceful, as 17 of the 31 $(54.8 \%)$ prospective studies were conducted by them. We suggest high-quality prospective research studies in the future from these resourceful countries to strengthen the available literature on the subject.

On the other hand, relatively simple studies also contribute to our knowledge on spinal TB, showing that centers with limited resources can also contribute to the body of evidence without the need for major research resources.

\section{Limitations}

Bibliometric analysis gives an overview of literature on a particular subject at one specific timepoint.
Due to the dynamic variations in global academic literature usage, citation numbers change every day. For instance, the most recently published article is by Papadopoulos et $\mathrm{al}^{23}$, published in 2015. It received 35 citations, was cited 7 times in 2019, and it has a citation rate of 7 per year. Looking into the citation density and number of publications in 2019, this article is likely to rise into the top 250 most cited articles in the future. Hence, it has the possibility to become a significant study in the current literature. This example highlights the fact that we need to focus not only on total citations but also on citation density and citations in recent years to keep up with the dynamic effects of younger but influential articles.

Article age is a significant factor in bibliometric analysis; the older the article, the more the citations it can get. Ottolenghi et $\mathrm{al}^{27}$ published their article in 1969, and it has been granted 91 citations, making this the 54th article in our list. In 2019, the article did not receive any new citations, which could question its significance in the current literature. Hence, total citations gained by an article alone cannot be used as a factor to assess the influence of the article on the subject.

One other limitation of our study is that we could not answer the trend of low citation rate of countries with high disease burden, which may be due to a low productivity itself or due to a low citation rate per se. Future research could address 
this limitation by analyzing the global research output of these specific countries.

\section{CONCLUSIONS}

This bibliometric study provides the 250 most influential articles on spinal TB. Most studies focused on surgical techniques and were Level 4 evidence. Our study serves to highlight the low impact of publications in the field of spinal TB from regions with high disease burden, especially the African continent. There is also a lack of prospective studies with a higher level of evidence on the subject. Collaborations of centers from low-income countries with a high burden of disease and centers from high research-output countries with sufficient resources may be a feasible solution to bridge this research gap.

\section{REFERENCES}

1. Fain O, Lortholary O, Lascaux VV, et al. Extrapulmonary tuberculosis in the northeastern suburbs of Paris: 141 cases. Eur J Intern Med. 2000;11(3):145-150.

2. Rajasekaran S, Soundararajan DCR, Shetty AP, Kanna RM. Spinal tuberculosis: current concepts. Global Spine J. 2018;8(4 Suppl):96S-108S. doi:10.1177/2192568218769053

3. Global tuberculosis report 2019. World Health Organization Web site. https://www.who.int/tb/publications/global_ report/en/. Accessed January 07, 2020.

4. De Vuyst D, Vanhoenacker F, Gielen J, Bernaerts A, De Schepper AM. Imaging features of musculoskeletal tuberculosis. Eur Radiol. 2003;13(8):1809-1819. doi:10.1007/s00330-0021609-6

5. Wang Y, Wang Q, Zhu R, et al. Trends of spinal tuberculosis research (1994-2015): a bibliometric study. Medicine (Baltimore). 2016;95(38):e4923. doi:10.1097/MD. 0000000000004923

6. Golden MP, Vikram HR. Extrapulmonary tuberculosis: an overview. Am Fam Physician. 2005;72(9):1761-1768.

7. Boyd HB. Global orthopaedics. J Bone Joint Surg Am. 1954;36(A:2):213-218.

8. Garfield E. Citation analysis as a tool in journal evaluation. Science. 1972;178(4060):471-479.

9. Chen LM, Liu YQ, Shen JN, et al. The 100 top-cited tuberculosis research studies. Int $J$ Tuberc Lung Dis. 2015;19(6):717-722. doi:10.5588/ijtld.14.0925

10. Rüegsegger N, Ahmad SS, Benneker LM, Berlemann U, Keel MJ, Hoppe S. The 100 most influential publications in cervical spine research. Spine. 2016;41(6):538-548. doi:10.1097/ BRS. 0000000000001261

11. Howick J, Chalmers I, Glasziou P, et al. The Oxford Levels of Evidence 2. Centre for Evidence-Based Medicine Web site. https://www.cebm.net/index.aspx?o=5653. Accessed January $7,2020$.

12. Hodgson AR, Stock FE, Fang HS, Ong GB. Anterior spinal fusion. The operative approach and pathological findings in 412 patients with Pott's disease of the spine. Br J Surg. 1960;48:172-178. doi:10.1002/bjs.18004820819

13. Hodgson A, Stock F. Anterior Spine Fusion for the Treatment of Tuberculosis of the Spine: The Operative Findings and Results of Treatment in the First One Hundred Cases. The Journal of Bone \& Joint Surgery. 1960 Mar;42(2):295-310.

14. Jain AK. Tuberculosis of the spine: a fresh look at an old disease. J Bone Joint Surg Br. 2010;92(7):905-913. doi:10.1302/ 0301-620X.92B7.24668

15. Moon MS. Tuberculosis of the spine. Controversies and a new challenge. Spine (Phila Pa 1976). 1997;22(15):1791-1797. doi:10.1097/00007632-199708010-00022

16. Ms M, Yk W, Ks L, Ky H, Ss K, Dh S. Posterior instrumentation and anterior interbody fusion for tuberculous kyphosis of dorsal and lumbar spines. Spine (Phila Pa 1976). 1995 Sep 1;20(17):1910-6.

17. Rajasekaran S, Soundarapandian S. Progression of kyphosis in tuberculosis of the spine treated by anterior arthrodesis. J Bone Joint Surg Am. 1989;71(9):1314-1323.

18. Yilmaz C, Selek HY, Gürkan I, Erdemli B, Korkusuz Z. Anterior instrumentation for the treatment of spinal tuberculosis. J Bone Joint Surg Am. 1999;81(9):1261-1267. doi:10. 2106/00004623-199909000-00007

19. Turgut M. Spinal tuberculosis (Pott's disease): its clinical presentation, surgical management, and outcome. A survey study on 694 patients. Neurosurg Rev. 2001;24(1):8-13. doi:10. 1007/p100011973

20. Kaufman DM, Kaplan JG, Litman N. Infectious agents in spinal epidural abscesses. Neurology. 1980;30(8):844-850. doi:10.1212/wnl.30.8.844

21. Rezai AR, Lee M, Cooper PR, Errico TJ, Koslow M. Modern management of spinal tuberculosis. Neurosurgery. 1995;36(1):87-98. doi:10.1227/00006123-199501000-00011

22. Burke HE. The Pathogenesis of Certain Forms of Extrapulmonary Tuberculosis. Am Rev Tuberc. 1950 Jul 1;62(1):48-67.

23. Papadopoulos EC, Boachie-Adjei O, Hess WF, et al. Early outcomes and complications of posterior vertebral column resection. Spine J. 2015;15(5):983-991. doi:10.1016/j. spinee.2013.03.023

24. Tuli SM. Results of treatment of spinal tuberculosis by “middle-path" regime. J Bone Joint Surg Br. 1975;57(1):13-23.

25. Salinas JL, Mindra G, Haddad MB, Pratt R, Price SF, Langer AJ. (2016) Leveling of tuberculosis incidence-United States, 2013-2015. MMWR Morb Mortal Wkly Rep. 2016;65(11):273-278. doi:10.15585/mmwr.mm6511a2

26. Held M, Castelein S, Bruins MF, et al. Most influential literature in spinal tuberculosis: a global disease without global evidence. Global Spine J. 2018;8(1):84-94. doi:10.1177/ 2192568217707182

27. Ottolenghi CE. Aspiration biopsy of the spine. Technique for the thoracic spine and results of twenty-eight biopsies in this region and over-all results of 1050 biopsies of other spinal segments. J Bone Joint Surg Am. 1969;51(8):1531-1544.

Disclosures and COl: On behalf of all authors, the corresponding author states that there is no conflict of interest with respect to the research, authorship, and publication of this article. The 
authors received no financial support for the research, authorship, and publication of this article.

Corresponding Author: Muthu Sathish, MS Ortho, Government Hospital, Velayuthampalayam, Karur, Tamil Nadu - 639117, India. Phone: +91 96008 56806; Email: drsathishmuthu@gmail.com.
Published 11 November 2020

This manuscript is generously published free of charge by ISASS, the International Society for the Advancement of Spine Surgery. Copyright (C) 2020 ISASS. To see more or order reprints or permissions, see http://ijssurgery.com. 